\title{
Quality Control of Pharmacopuncture: A Comparative Study of Good Manufacturing Practice and External Herbal Dispensary Standards
}

\author{
Ji-Eun Han ${ }^{1}$, Minjung Park ${ }^{2}$, Tteul-E-Bom An ${ }^{3}$, Jong-Hyun Park ${ }^{4}$, Danny Oh ${ }^{5}$, Kyeong Han Kim ${ }^{6}$, \\ Soo-Hyun Sung ${ }^{1}$ *
}

${ }^{1}$ Department of Policy Development, National Development Institute of Korean Medicine, Seoul, Republic of Korea

${ }^{2}$ National Agency for Development of Innovative Technologies in Korean Medicine, Seoul, Republic of Korea

${ }^{3}$ Kind Cloud Korean Medicine Clinic, Jinju, Republic of Korea

${ }^{4}$ Department of Pathology, College of Korean Medicine, Dae-Gu Haany University, Gyeongsan, Republic of Korea

${ }^{5}$ Grauate School of Social Welfare, Soongsil University, Seoul, Republic of Korea

${ }^{6}$ Department of Preventive Medicine, College of Korean Medicine, Woosuk University, Wanju, Republic of Korea

Received March 31, 2021

Reviewed April 2, 2021

Accepted April 14, 2021

\section{*Corresponding Author}

Kyeong Han Kim

Department of Preventive Medicine,

College of Korean Medicine, Woosuk University, 443, Samnye-ro, Samnye-eup, Wanju 55338, Republic of Korea Tel: +82-63-290-9031

E-mail: solip922@hanmail.net

\section{Soo-Hyun Sung}

Department of Policy Development, National Development Institute of Korean Medicine, 173, Toegye-ro, Junggu, Seoul 04554, Republic of Korea Tel: +82-2-3393-4531

E-mail: koyote10010@nikom.or.kr
Objectives: We aimed to compare the external herbal dispensary (EHD) evaluation criteria for pharmacopuncture and the Korea Good Manufacturing Practice (KGMP) sterile medicine standards to contribute to the establishment of quality control criteria for pharmacopuncture.

Methods: We obtained the KGMP standards from the Ministry of Food and Drug Safety and the pharmacopuncture certification criteria from the Ministry of Health and Welfare of South Korea. The EHD evaluation items were classified into three categories: facilities, quality control, and validation. The evaluation items were compared with the KGMP sterile medicine criteria to determine their conformance with each other, followed by a discussion among the committee of six experts and their consensus to suggest the items to complement the EHD evaluation criteria.

Results: Among the KGMP sterile medicine criteria, 44 were related to the management of the facilities, and 32 pharmacopuncture evaluation items corresponded to these KGMP items (66.7\%). Fifty-eight KGMP criteria were related to quality management, and 42 pharmacopuncture evaluation items corresponded to these KGMP items (72.4\%). Twentyfive KGMP sterile medicine criteria were related to validation, and 11 pharmacopuncture evaluation items corresponded to these KGMP items (44.0\%). Sixteen items under the pharmacopuncture EHD criteria corresponded to the KGMP sterile medicine criteria based on the consent of the experts. Among these, 4 were related to facility management, 6 were related to quality control, and 6 were related to validation.

Conclusion: For the safety and quality control of pharmacopuncture, there is a need to select the criteria for the mandatory items among the proposed pharmacopuncture-EHD criteria laws and systems to ensure that the pharmacopuncture materials are produced under the pharmacopuncture-EHD in compliance with the relevant requirements. More studies are needed to secure the safety level of pharmacopuncture materials corresponding to that of conventional medicine.

Keywords: quality control, pharmacopuncture, good manufacturing practice (GMP), external herbal dispensary 


\section{ABBREVIATIONS}

EHD, external herbal dispensary; GMP, good manufacturing practice; MFDS, ministry of food and drug safety; KGMP, Korea good manufacturing practice; $\mathrm{P}-\mathrm{EHD}$, pharmacopunctureEHD; TKM, traditional Korean medicine.

\section{INTRODUCTION}

Pharmacopuncture is a new form of acupuncture in which herbal medicine is injected into acupuncture points. Based on the theories of traditional Korean medicine (TKM), TKM doctors can use this treatment method to treat various diseases $[1,2]$. In Korea, pharmacopuncture has been covered under automobile insurance, which is the official insurance of the country since 2009 [3]. It is also a frequently used treatment, and approximately $37.4 \%$ of the patients treated in TKM clinics have experienced pharmacopuncture treatment $[4,5]$. Pharmacopuncture is currently being used to treat skin diseases $[6$, 7], mental illness [8], arthritis [9], musculoskeletal diseases [2, 10], circulatory diseases [11], and gastric disease [12]. It is also being used as a part of cancer care to address chemotherapyinduced nausea and vomiting [13].

Currently, pharmacopuncture fluids are being prepared at external herbal dispensaries (EHDs) or TKM clinics, rather than by pharmaceutical companies [14]. There were no quality control standards for the preparation of pharmacopuncture fluids in South Korea until 2018 when the Ministry of Health and Welfare introduced the EHD evaluation and certification program, providing a set of criteria for the pharmacopuncture fluids for the first time [15]. Currently, the pharmacopuncture accreditation program is in effect in the form of issuing government certificates after evaluating the conformance of the EHDs with the Korea Good Manufacturing Practice (KGMP), which is valid for three years [15].

Pharmacopuncture is similar in nature to injections in conventional medicine. Injection products (sterile medicines) are subject to quality control in accordance with the Good Manufacturing Practice (GMP) standards approved by the Ministry of Food and Drug Safety (MFDS) $[15,16]$. GMP refers to a set of quality control criteria for the entire process of medicine production ranging from the purchase of production equipment and raw materials to production and packaging. The set of criteria in effect in South Korea is referred to as the KGMP. The corresponding criteria in Europe and in the United States are the euGMP and cGMP (or current GMP), respectively [1719].

In a previous study, we examined how the quality of pharmacopuncture was controlled by the government through the EHD accreditation system [15]. In addition, a study was conducted to examine the status of the facilities and the quality control of herbal medicines prepared in EHDs and to compare them with the KGMP [20]. However, no study has compared the management standards for pharmacopuncture and the KGMP sterile medicine criteria.

The present study aimed to investigate the EHD evaluation criteria for pharmacopuncture and the KGMP sterile medicine standards and to provide additional accreditation criteria (proposed) for the safe use and quality control of pharmacopuncture. Moreover, this study aimed to contribute to the integration of pharmacopuncture, a treatment based on TKM, into the healthcare system.

\section{MATERIALS AND METHODS}

\section{Overview of the study}

In this study, the researchers initially compared the regulations for the production of sterile medicines under the KGMP with each of the corresponding items under the evaluation criteria for pharmacopuncture EHDs (P-EHD) to identify the similarities and differences between them. This was followed by the formation of an expert group that made suggestions for the proposed additional EHD evaluation criteria for pharmacopuncture based on their consensus.

\section{Literature review}

To review the KGMP criteria for sterile medicines used by South Korean pharmaceutical companies, we searched the official documents on the website of South Korea's MFDS and secured the production standards for sterile medicinal products [21]. Three documents were selected according to the search [22-24]. To review the criteria for the production of pharmacopuncture fluids prepared in EHDs, we searched the official documents on the website of South Korea's Ministry of Health and Welfare [25] and certification standards of external herbal dispensary was selected [26].

The evaluation items for pharmacopuncture were classified into three parts: facility, quality control, and validation. These 
items were compared with the KGMP evaluation items for sterile medicines to study the similarity between these two sets of criteria. For each of these three categories, the evaluation items under the KGMP that did not have corresponding items in the EHD evaluation were separately identified.

\section{Expert consensus}

To suggest additional EHD evaluation criteria for pharmacopuncture, an advisory committee of experts was formed. The expert group consisted of six members: three internal researchers (including a TKM specialist with more than 10 years of experience in the field, a professor from a TKM university with more than 20 years of experience in the field, and one TKM policy researcher who was a project investigator for accreditation of EHDs of TKM institutions) and three external experts. The external experts included a GMP consultant for quality control and validation, a general manager of an EHD with more than 9 years of experience in preparing pharmacopuncture fluids, and a quality control team leader from a pharmaceutical company that manufactured herbal drugs.

The experts discussed development strategies for quality management of pharmacopuncture, focusing on the comparison table between the KGMP and the EHD evaluation items. After two sessions, the committee identified a list of items to be included in the EHD evaluation criteria. After sufficient discussions, considering a direct impact on the safety of the preparation of pharmacopuncture fluids as the key principle, each additional item was included in the criteria when at least five out of six members of the committee approved.

\section{RESULTS}

\section{Comparison between the KGMP criteria and the EHD evaluation items}

The EHD evaluation items for pharmacopuncture were classified into three categories: facilities, quality control, and validation. They were compared with the items from the KGMP sterile medicine production criteria to study the level of similarity between these two sets of criteria. This comparison revealed the proportion of correspondence between the EHD criteria and the KGMP criteria (Table 1). Among the KGMP sterile medicine criteria, 44 were related to the management of the facilities, and 32 pharmacopuncture evaluation items corresponded to
Table 1. Comparison between the standard for sterile medicine under the KGMP and the evaluation criteria for pharmacopuncture

\begin{tabular}{lcc}
\hline & $\begin{array}{c}\text { KGMP standard for } \\
\text { sterile medicines } \\
(\mathrm{n}, \%)\end{array}$ & $\begin{array}{c}\text { EHD standard for } \\
\text { pharmacopuncture } \\
(\mathrm{n}, \%)\end{array}$ \\
\hline Facility management & $44(100 \%)$ & $32(72.7 \%)$ \\
Quality control & $58(100 \%)$ & $42(72.4 \%)$ \\
Validation & $25(100 \%)$ & $11(44.0 \%)$ \\
Total & $127(100 \%)$ & $85(66.9 \%)$ \\
\hline
\end{tabular}

EHD, External Herbal Dispensary; KGMP, Korea Good Manufacturing Practice.

these KGMP items (72.7\%). Fifty-eight KGMP criteria were related to quality management, and 42 pharmacopuncture evaluation items corresponded to these KGMP items (72.4\%). Twenty-five KGMP sterile medicine criteria were related to validation, and 11 pharmacopuncture evaluation items corresponded to these KGMP items (44.0\%).

\section{A review of the KGMP items that were not included in the pharmacopuncture evaluation criteria}

Among the facility management standards for sterile medicines under the KGMP, 12 items were not included in the EHD standards. These items were related to the use of isolator technology, controlling the temperature and humidity based on the job characteristics, and blowing/charging/sealing management. Among the quality control standards for sterile medicines under the KGMP, 16 items were not included in the EHD standards. These were related to the control of contamination by microorganisms, minimizing the gaps between production phases, and filtering conditions. Fourteen items from the validation standards for sterile medicines under the KGMP were not included in the EHD standards.

\section{The updated EHD evaluation criteria for pharmacopuncture (draft)}

Based on the consensus of the experts, we identified 16 items from the KGMP standards for sterile medicines that could be included in the criteria for pharmacopuncture medicines prepared in EHDs (Table 2). Among these, 4 items belonged to facility management, 6 were related to quality control, and 6 were related to validation. 
Ji-Eun Han, et al.

Table 2. A proposed application of the criteria for pharmacopuncture in EHDs based on the standard for sterile medicine

\begin{tabular}{|c|c|c|c|}
\hline Items & & Application to the EHD pharmacopuncture criteria (draft) & $\begin{array}{l}\text { EHD } \\
\text { Accreditation criteria-related parts }\end{array}$ \\
\hline \multirow[t]{4}{*}{$\begin{array}{l}\text { Facility } \\
\text { management }\end{array}$} & 1 & $\begin{array}{l}\text { Temperature, relative humidity, and other characteristics are different } \\
\text { depending on the nature of the job to be done and the product in question. } \\
\text { Such parameters shall not adversely affect the cleanliness levels required. }\end{array}$ & $\begin{array}{l}\text { 1.1 Facility Management } \\
\text { 8.3 Filtration Work Management of } \\
\text { Pharmacopuncture Preparation }\end{array}$ \\
\hline & 2 & $\begin{array}{l}\text { Due to the special technical needs, special care is needed for the following } \\
\text { items as the minimum. 1) Equipment design and qualification, 2) } \\
\text { reproductivity and validation of cleaning-in-place and sterilization-in-place, } \\
\text { 3) the surrounding environment of the cleanliness workroom where the } \\
\text { equipment is located, 4) training of staff and their work uniform, 5) the } \\
\text { intervention of equipment in all significant points including aseptic assembly } \\
\text { of all equipment before filling. }\end{array}$ & $\begin{array}{l}\text { 8.3 Filtration Work Management of } \\
\text { Pharmacopuncture Preparation }\end{array}$ \\
\hline & 3 & $\begin{array}{l}\text { If the maintenance of equipment is done in a cleanliness area and the } \\
\text { cleanliness levels and/or aseptic conditions are not maintained, cleaning, } \\
\text { disinfecting, and/or sterilization of the relevant area is required before } \\
\text { restarting the process. }\end{array}$ & $\begin{array}{l}\text { 1.2 Preparation Supporting } \\
\text { Facilities }\end{array}$ \\
\hline & 4 & $\begin{array}{l}\text { Handle the material, containers, equipment in a way to prevent contamination } \\
\text { after final washing. }\end{array}$ & 1.1 Facility Management \\
\hline \multirow[t]{4}{*}{ Quality control } & 1 & $\begin{array}{l}\text { For classification, use a portable particulate matter counter with a shorter } \\
\text { sample tubing. This is because, for a system that takes samples from a long } \\
\text { distance using a longer tubing, the deposit rate of the particles of } 5.0 \mu \mathrm{m} \text { or } \\
\text { larger increases. In a uni-directional air flow system, use an isokinetic sample } \\
\text { head. }\end{array}$ & $\begin{array}{l}\text { 2.2 Monitoring of Clean Room and } \\
\text { Air Conditioning Equipment }\end{array}$ \\
\hline & 2 & $\begin{array}{l}\text { To be classified as "In Operation," the item must be proven for the worst case. } \\
\text { An item can be proven for the worst case in a simulation or a during a media } \\
\text { fill. For more information on the tests that verify whether the cleanliness class } \\
\text { is maintained, see EN/ISO 14644-2. }\end{array}$ & $\begin{array}{l}\text { 1.1 Facility Management } \\
2.1 \text { Classification of Clean Room } \\
\text { and Air Conditioning Equipment }\end{array}$ \\
\hline & 5 & $\begin{array}{l}\text { The intervals between cleaning, drying, and sterilization of equipment, } \\
\text { materials, and containers and the gaps between sterilization and the use } \\
\text { thereafter must be minimized. Such intervals must be in consideration of the } \\
\text { proper period for the storage conditions. }\end{array}$ & 1.1 Facility Management \\
\hline & 6 & $\begin{array}{l}\text { Check the bioburden prior to the sterilization process. In consideration of the } \\
\text { efficiency of the sterilization method in use, set the limit of contamination } \\
\text { prior to sterilization. A bioburden test must be conducted for each batch of } \\
\text { products for aseptic filling and those of final sterilization. As for the product of } \\
\text { final sterilization with overkill sterilization parameters, it is allowed to check } \\
\text { the bioburden only in pre-meditated intervals. To use a parametric release } \\
\text { system, bioburden testing must be conducted for each batch, which shall be } \\
\text { considered as a process test. If applicable, the level of endotoxin should be } \\
\text { checked. All solutions, especially a large-volume fluid product, must be filtered } \\
\text { using a micro-organism retaining filter, which should be used immediately } \\
\text { before filling whenever possible. }\end{array}$ & $\begin{array}{l}\text { 8.4 Final Work Management of } \\
\text { Pharmacopuncture Preparation }\end{array}$ \\
\hline
\end{tabular}


Table 2. Continued

\begin{tabular}{|c|c|c|c|}
\hline Items & & Application to the EHD pharmacopuncture criteria (draft) & $\begin{array}{c}\text { EHD } \\
\text { Accreditation criteria-related parts }\end{array}$ \\
\hline \multirow[t]{5}{*}{ Validation } & 1 & $\begin{array}{l}\text { The validation of an aseptic process must include a process simulation test } \\
\text { using a nutrient medium. The nutrient medium must be selected based on the } \\
\text { formulation of the product, optionality, transparency, density, and suitability of } \\
\text { the nutrient medium for sterilization. }\end{array}$ & 8.6 Preparation in Advance \\
\hline & 2 & $\begin{array}{l}\text { A process simulation test must be as close to the usual manufacturing } \\
\text { process as possible and include all significant steps of production. The test } \\
\text { must consider the worst case as well as various interference using usual } \\
\text { production. }\end{array}$ & 8.6 Preparation in Advance \\
\hline & 3 & $\begin{array}{l}\text { To pass a process simulation test, three consecutive tests in each shift must } \\
\text { yield qualifying results, and the tests shall be repeated at given intervals. } \\
\text { A test must also be conducted after a major alteration of the HVAC system, } \\
\text { facilities, processes, or the number of shifts. Usually, a process simulation } \\
\text { test is required twice a year for each shift and process. However, in the case } \\
\text { of radiational medicines, the number of process simulation tests can be } \\
\text { adjusted if justified with clear evidence. }\end{array}$ & 8.6 Preparation in Advance \\
\hline & 4 & $\begin{array}{l}\text { Before selecting a sterile process, use physical measurement methods and } \\
\text { appropriate biological indicators to validate and qualify the products with } \\
\text { regard to compliance with expected sterility requirements for different loading } \\
\text { patterns. The validity of a process must be verified regularly, at least once a } \\
\text { year, or whenever there is a significant change with equipment. The results of } \\
\text { such verification must be preserved. }\end{array}$ & 8.6 Preparation in Advance \\
\hline & 5 & $\begin{array}{l}\text { Validate using proper biological indicators for each sterilization cycle. For all the } \\
\text { load, test pieces in proper numbers should be used. The information obtained } \\
\text { in this process must be documented in production documents. }\end{array}$ & 8.6 Preparation in Advance \\
\hline
\end{tabular}

\section{DISCUSSION}

Pharmacopuncture is a treatment method in which herbal extracts are injected into acupuncture points using injectors. It is an innovative treatment that changes the administration paths of herbal medicines by combining TKM treatments with modern tools. The effects of pharmacopuncture can be immediately observed after treatment, as herbal extracts are directly absorbed without the need to pass through the gastrointestinal tract [1]. Owing to the above-mentioned benefits/attributes pharmacopuncture has become one of the representative treatment options in TKM clinics.

Pharmacopuncture medicines are included in the preparation of herbal medicines. Therefore, they are prepared in EHDs. Thus, it is necessary to control this process using strict criteria, since the herbal ingredients used in this process are types of medicines. Particularly, the medicines that are injected percuta- neously or into the muscle at acupuncture points must comply with the requirements for sterile medicines (injections). However, a government-level accreditation regime still remains a challenge.

Currently, South Korea has approved the operation of EHDs, which are external facilities separate from medical clinics and are used for the preparation of herbal concoctions [14]. However, unlike the provisions for conventional medicine, the provisions regarding the operation and management of EHDs in the Medical Service Act and the Enforcement Rules for the Medical Service Act are not sufficient to ensure standardization, validity, and safety of herbal medicines. The "Guideline for the Installation and Use of EHDs and Shared Use of Dispensaries" covers only the minimum guidelines for the installation and operation of EHDs, management and supervision of EHDs, and shared use of dispensaries [14] without providing detailed guidelines for the management of the preparation processes of 
herbal medicines while operating an actual EHD. Hence, these guidelines are not sufficient to ensure methodical management of facilities and safety of the prepared medicines.

To overcome these issues, the government introduced the EHD accreditation program, which was designed to ensure safe preparation of herbal medicines. This accreditation program covers not only the operation of the dispensary but also the entire process from the admission of raw materials to storage, preparation, packaging, and shipping [26]. Particularly, the accreditation program also covers pharmacopuncture with 218 items that correspond to the items included in the KGMP, including but not limited to setting a clean area, management of the environment, and sterile processes (165 mandatory items and 53 recommended items). However, it is necessary to continue the discussions and amendments to the criteria to verify that pharmacopuncture medicines are being prepared safely. Thus, the purpose of this study was to compare the EHD evaluation criteria with the KGMP sterile medicine criteria to improve the quality control of pharmacopuncture.

The results of this study showed that the EHD evaluation criteria included 32 out of 44 items related to facility management (66.7\%), 42 out of 58 items related to quality control (72.4\%), and 11 out of 25 items related to validation (44.0\%) among the KGMP sterile medicine criteria.

An EHD is an auxiliary facility of a medical institution and is not intended for mass production of medicines to be marketed. EHDs are used to prepare medicines customized to the prescription provided by a TKM doctor to supply 14,000 individual TKM clinics. Therefore, it is difficult to expand these facilities beyond a certain size. Hence, an approach to increase the number of evaluation items related to the quality control and validation categories, rather than those related to the facility management category, is necessary.

The current EHD accreditation criteria for pharmacopuncture include $66.7 \%$ of the items from the facility management category, which is a relatively higher proportion. The category with the highest inclusion rate was quality control (72.4\%), while the category of validation had the lowest inclusion rate of 44.0\%, which necessitates improvement.

Based on the consensus among experts, we presented the additional P-EHD evaluation criteria (draft), selecting 12 out of $16(75 \%)$ items for quality control and validation. In the quality control category, six items, including the management of the raw materials, setting the cleanliness level for the job, and minimizing contamination in all processes, were selected. To ensure sterility of medicines, it is necessary to meticulously manage the entire process from the intake of raw materials to the shipping of finished products [27]. We also included six items from the quality control category, including the simulation of validation in a clean environment, detailed settings, and maintenance of sterility for different loading types. A validation system ensures that a specific process continues to produce products that comply with the previously set standards and quality requirements [28]. Therefore, stepwise introduction or government support must be considered, since pharmacopuncture is used in more than 14,000 TKM clinics.

The present study has some limitations. Pharmacopuncture fluids, which are administered based on the theories of traditional medicine and conventional injections are inherently different types of medicines. However, since pharmacopuncture shares the same administrative path, it must satisfy the requirements for sterile medicines. Hence, it was assumed that these two types of medicines should be managed based on production processes at similar levels when we set the direction for this study. Pharmacopuncture shares some properties with sterile medicines such as injections. However, it is a branch of traditional medicine that has been in clinical use for more than five decades since 1967 [29]. The Food and Drug Safety Ministry of the European Union recognizes the safety of traditional medicine that has been in use for a certain period, while the MFDS of South Korea does so for traditional medicine based on oriental books that recorded the details of ancient medicines [30, 31]. Hence, in-depth discussion is necessary about the extent to which the safety of pharmacopuncture should be recognized by the government and about identification of the parts that should be institutionally managed. Another limitation is that the process of considering the opinions of the groups that actually produce pharmacopuncture medicines in EHDs and the opinions of the general population were omitted while deciding the study direction and making the proposal for inclusion. Due to the nature of this study (a policy development project), the harmony between policymaking and public opinion (e.g., opinion of the general population and the stakeholders of P-EHDs) is essential [32].

Nevertheless, this study is the first one to compare the KGMP sterile medicine criteria and the criteria for P-EHDs, which makes it valuable. Furthermore, it would be possible to improve the safety and quality control of pharmacopuncture if the suggestions from this study are reflected in the P-EHD accreditation program. 
Considering future challenges, it is necessary to enhance the evaluation criteria for P-EHD. In addition, the current P-EHD criteria constitute a self-regulated system. Therefore, it is still possible for P-EHDs to prepare pharmacopuncture medicines, regardless of the evaluation criteria. Therefore, for the safety and quality control of pharmacopuncture [26], there is a need to select the criteria for the mandatory items among the P-EHD evaluation criteria and to update the laws and systems to ensure that the pharmacopuncture materials are produced under the P-EHD in compliance with the relevant requirements. The manufacturing criteria for medicines are internationally harmonized in accordance with the guidelines of the International Council of Harmonization [33]. For successful integration of pharmacopuncture in the healthcare system, it is necessary to manage it to an acceptable degree in accordance with the GMP standards.

\section{CONCLUSION}

By comparing the KGMP sterile medicine standards and the EHD certification standards, our study showed the level of compliance of the pharmacopuncture criteria with the KGMP criteria for sterile medicines with respect to three categories (facility management, quality control, and validation). In addition, we suggested 16 items to complement the current EHD evaluation criteria based on the consensus among experts. These findings will be used in the process of updating of pharmacopuncture EHD certification standards and will contribute to the quality control of pharmacopuncture. More studies are needed in the future to secure the safety of pharmacopuncture to the same level as that used for conventional medicine.

\section{CONFLICT OF INTEREST}

The authors declare that there are no conflicts of interest regarding the publication of this paper.

\section{FUNDING}

This research was supported by a grant from the Project of National Development Institute of Korean Medicine, Accreditation of External Herbal Dispensaries of Traditional Korean Medicine Clinics, funded by the Korea Ministry of Health and Welfare.

\section{ETHICS APPROVAL AND CONSENT TO PARTICIPATE}

Not applicable.

\section{AVAILABILITY OF DATA AND MATERIALS}

The datasets used and/or analyzed during the current study are available from the corresponding author upon reasonable request.

\section{AUTHORS' CONTRIBUTION}

JEH, JHP, KHK and SHS designed the study. JEH and TEA completed the literature review and compared collected data. JEH, KHK, SHS wrote the drafted manuscript. MP, JHP and DO reviewed the manuscript. All authors have read and approved the final manuscript.

\section{ORCID}

Ji-Eun Han, https://orcid.org/0000-0001-9014-0354

Minjung Park, https://orcid.org/0000-0003-2219-9666

Tteul-E-Bom An, https://orcid.org/0000-0002-1045-0561

Jong-Hyun Park, https://orcid.org/0000-0002-7220-2328

Danny Oh, https://orcid.org/0000-0001-8737-3210

Kyeong Han Kim, https://orcid.org/0000-0003-4868-9145

Soo-Hyun Sung, https://orcid.org/0000-0001-7606-0147

\section{REFERENCES}

1. Park J, Lee H, Shin BC, Lee MS, Kim B, Kim JI. Pharmacopuncture in Korea: a systematic review and meta-analysis of randomized controlled trials. Evid Based Complement Alternat Med. 2016;2016:4683121.

2. Lee YJ, Shin JS, Lee J, Kim MR, Park KB, Lee HD, et al. Usage report of pharmacopuncture in musculoskeletal patients visiting Korean medicine hospitals and clinics in Korea. BMC Complement Altern Med. 2016;16(1):292.

3. Kim DH, Cho SJ, Ko JA. Policy improvement plan based on Korean medicine use. Wonju: Health Insurance Review \& Assessment Service; 2015. 185 p.

4. Shin YS, Shin JS, Lee J, Lee YJ, Kim MR, Ahn YJ, et al. A survey among Korea Medicine doctors (KMDs) in Korea on patterns of integrative Korean Medicine practice for lumbar intervertebral disc displacement: preliminary research for clinical practice 
guidelines. BMC Complement Altern Med. 2015;15(1):432.

5. Park JE. A survey on Korean medicine doctor's use of Herbal Acupuncture and recognition of its national health insurance coverage [master's thesis]. [Seoul]: Kyung Hee University; 2018. $68 \mathrm{p}$.

6. Kim S, Lee J, Shin M. Mesotherapy with snake venom pharmacopuncture to treat hand eczema: two cases report. J Pharmacopuncture. 2020;23(4):273-6.

7. Lee IS, Kang KS, Kim SY. Panax ginseng pharmacopuncture: current status of the research and future challenges. Biomolecules. 2019;10(1):33.

8. Jittiwat J, Wattanathorn J. Ginger pharmacopuncture improves cognitive impairment and oxidative stress following cerebral ischemia. J Acupunct Meridian Stud. 2012;5(6):295-300.

9. Yamasaki SC, Mendes MT, Alponti RF, Silveira PF. Efficacy of parenteral administration of bee venom in experimental arthritis in the rat: a comparison with methotrexate. Toxicon. 2015;98:75-88.

10. Shen L, Lee JH, Joo JC, Park SJ, Song YS. Bee venom acupuncture for shoulder pain: a systematic review and meta-analysis of randomized controlled trials. J Pharmacopuncture. 2020;23(2): 44-53.

11. Noh JH, Park JA, Youn HM, Jang KJ, Song CH, Ahn CB, et al. The effect of Hominis Placenta Pharmacopuncture on leg spasticity of stroke patients (a pilot study, double blind, randomized, controlled clinical trial). J Pharmacopuncture. 2009;12(4):97110.

12. Park JW, Yoon SW, Kim JS, Ryu BH. A clinical pilot study of Carthami-Semen herbal acupuncture treatment for chronic constipation. J Korean Acupunct Moxib Soc. 2008;25(5):127-37.

13. Cheon S, Zhang X, Lee IS, Cho SH, Chae Y, Lee H. Pharmacopuncture for cancer care: a systematic review. Evid Based Complement Alternat Med. 2014;2014:804746.

14. Ministry for Health, Welfare and Family affairs. Guideline on installation and utilization of external herbal dispensaries of traditional Korean medicine clinics and share-use of herbal dispensaries. Sejong: Ministry for Health, Welfare and Family affairs; 2009. $14 \mathrm{p}$.

15. Sung SH, Shin BC, Park MJ, Kim KH, Kim JW, Ryu JY, et al. Current status of management on pharmacopuncture in Korea through introduction of an accreditation system. J Pharmacopuncture. 2019;22(2):75-82.

16. Wacker M. Nanocarriers for intravenous injection--the long hard road to the market. Int J Pharm. 2013;457(1):50-62.

17. International Council for Harmonisation ( $\mathrm{ICH})$. Q7 - good manufacturing practice guide for active pharmaceutical ingredients. Geneva: International Council for Harmonisation (ICH); 2000. 43 p.
18. Current Good Manufacturing Practice (CGMP) Regulations [Internet]. Silver Spring: U.S. Food \& Drug Administration; 2020 Sep 21 [cited 2021 Jan 12]. Available from: https://www. fda.gov/drugs/pharmaceutical-quality-resources/current-goodmanufacturing-practice-cgmp-regulations.

19. Good Manufacturing Practice (GMP) Guidelines [Internet]. Brussels: European Commission; [cited 2021 Jan 12]. Available from: https://ec.europa.eu/health/documents/eudralex/vol-4_ en.

20. Sung SH, Han JE, Ryu JY, Sung AD, Park JY, Ha IH, et al. Current status and future perspective of external herbal dispensaries preparing traditional herbal medicine in South Korea: the first National-Wide Survey results. BMC Complement Med Ther. 2020;20(1):354.

21. Korea Ministry of Food and Drug Safety [Internet]. Cheongju: Korea Ministry of Food and Drug Safety; [cited 2021 Jan 21]. Available from: https://www.mfds.go.kr/eng/index.do.

22. Regulations on Drug Manufacture and Qualilty Control [Internet]. Cheongju: Ministry of Food and Drug Safety; 2018 Nov 30 [cited 2021 April 15]. Available from: https://www.law.go.kr/ LSW/admRulLsInfoP.do?admRulSeq=2100000176361.

23. Degree on Facility Standards for Manufacturing Business and Importers of Drugs, Etc. [Internet]. Cheongju: Ministry of Food and Drug Safety; 2019 Nov 11 [cited 2021 April 15]. Available from: https://www.law.go.kr/\%EB\%B2\%95\%EB\%A0\%B9/\%EC\% 9D\%98\%EC\%95\%BD\%ED\%92\%88\%EB\%93\%B1\%EC\%9D\%98 \%ЕC\%A0\%9C\%ЕC\%A1\%B0\%ЕC\%97\%85\%ЕB\%B0\%8F\%ЕC\% 88\%98\%EC\%9E\%85\%ЕC\%9E\%90\%ЕC\%9D\%98\%EC\%8B\%9C \%ЕC\%84\%A4\%EA\%B8\%B0\%ЕC\%A4\%80\%ЕB\%А0\%B9\%ЕC\% 8B\%9C\%ED\%96\%89\%ЕA\%B7\%9C\%ЕC\%B9\%99.

24. Rules on Saftey of Drug. Etc. [Internet]. Cheongju: Ministry of Food and Drug Safety; 2020 Oct 14 [cited 2021 April 15]. Available from: https://www.law.go.kr/\%EB\%B2\%95\%EB\%A0\%B9/\% EC\%9D\%98\%EC\%95\%BD\%ED\%92\%88\%EB\%93\%B1\%EC\%9D \%98\%EC\%95\%88\%EC\%A0\%84\%EC\%97\%90\%EA\%B4\%80\%E D\%95\%9C\%EA\%B7\%9C\%EC\%B9\%99.

25. Korea Ministry of Health and Welfare [Internet]. Sejong: Korea Ministry of Health and Welfare; [cited 2021 Jan 21]. Available from: http://www.mohw.go.kr/eng/index.jsp.

26. Korea Ministry of Health and Welfare. Certification standards of external herbal dispensary. Sejong: Korea Ministry of Health and Welfare; 2018. 177 p.

27. U.S. Food and Drug Administration. Guidance for industry, sterile drug products produced by aseptic processing - current good manufacturing practice. Rockville: U.S. Food and Drug Administration; 2004. 59 p.

28. Hoffmann A, Kähny-Simonius J, Plattner M, Schmidli-Vckovski V, Kronseder C. Computer system validation: an overview of of- 
ficial requirements and standards. Pharm Acta Helv. 1998;72(6): 317-25.

29. Korean Pharmacopuncture Institute. Pharmacopuncturology. 2nd ed. Seoul: Elsevier Korea; 2011. 530 p.

30. Choi DW, Kim JH, Cho SY, Kim DH, Chang SY. Regulation and quality control of herbal drugs in Korea. Toxicology. 2002;181182:581-6.

31. Knoess W, Wiesner J. The globalization of traditional medicines: perspectives related to the European union regulatory environ- ment. Engineering. 2019;5(1):22-31.

32. Dobuzinskis L, Howlett M, Laycock D. Policy analysis in Canada: the state of the art. Toronto: University of Toronto Press; 2007. $603 \mathrm{p}$.

33. Lindström-Gommers L, Mullin T. International conference on harmonization: recent reforms as a driver of global regulatory harmonization and innovation in medical products. Clin Pharmacol Ther. 2019;105(4):926-31. 